\title{
Extraño caso de polaquiuria
}

\author{
R. Liendo, C. Palma \\ Servicio de Urología. Hospital Clínico Universidad de Chile. Santiago de Chile.
}

Actas Urol Esp 2006; 30 (2): 236

$\mathrm{U}^{\mathrm{n}}$ n joven de 15 años que vive en Santiago, Chile. Se presentó con una historia de 6 meses de evolución caracterizada por nicturia y polaquiuria. El examen físico revelaba una gran masa de $10 \mathrm{~cm}$ de diámetro en el hipogastrio.

La ecotomografía informaba una gran masa retroperitoneal. En la resonancia nuclear magnética (RNM) se observa una imagen hipointensa en

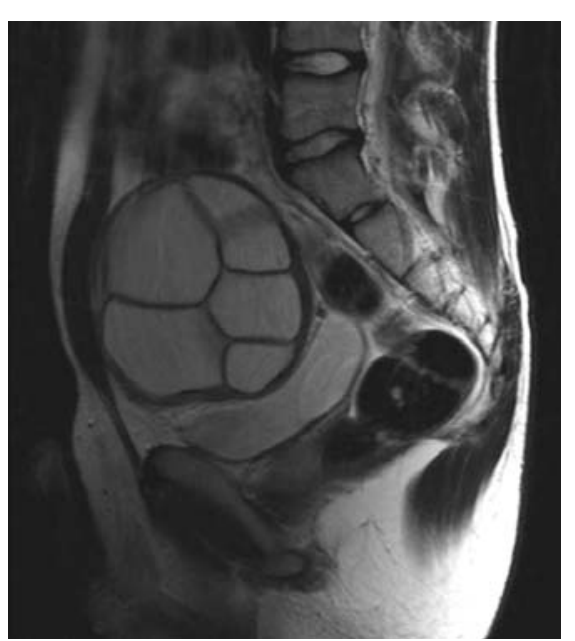

FIGURA 1A. RMN potenciado en T1, corte sagital, demostrando imagen quistica multiloculada retroperitoneal.

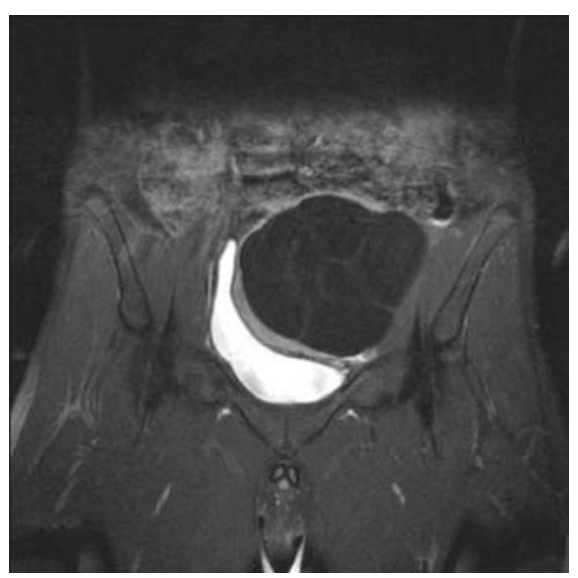

FIGURA 1C. RMIN potenciado en T2, corte coronal, con contraste $\mathrm{EV}$.
T1 (A) e hiperintensa en T2 (B) de aspecto quístico homogéneo, de contornos bien definidos, cuyos septos y pared realzan tras la administración de contraste endovenoso (C), la cual mide aproximadamente 11,2 × 8,8 x 8,9 cm. La lesión descrita contacta y desplaza la pared abdominal anterior produciendo un efecto similar en la vejiga y el sigmoides. Impresión radiológica: lesión quística multiloculada en pelvis mayor, entre sus diagnósticos diferenciales se debe considerar quiste mesentérico, linfangioma, menos probablemente hidatíco.

En el acto quirúrgico se encontró una gran masa adherida a la vejiga, vasos iliacos, desplazando ambos deferentes y uréteres con grandes cambios anatómicos. Anatomía patológica confirma quiste hidatídico (D). Chile es uno de los países con la mayor incidencia de Equinococcus Granulosus, con aproximadamente 700 a 800 nuevos casos por año. Se presenta en áreas rurales del país y afecta principalmente el hígado (59-75\%), pulmones (27\%), riñón (3\%), huesos (1-4\%) y cerebro (1-2\%).

Dr. R. Liendo

E-mail: roliendo@hotmail.com

(Trabajo recibido el 4 de mayo 2005) 